\title{
Gender Differences in Marital Disruption among Patients with Cancer: Results from the Korean National Health and Nutrition Examination Survey (KNHANES)
}

\author{
Hai-Yan Song ${ }^{1,2}$, Jeoung-A Kwon ${ }^{1,2}$, Jae-Woo Choi ${ }^{1,2}$, Sun-Jung Kim ${ }^{1,2}$,Eun-Cheol \\ Park $^{2,3 *}$
}

\begin{abstract}
Background: Cancer is a major life event that imposes huge economic and mental burdens on patients and families. In addition, the diagnosis of cancer also causes significant family discordance that can lead to marital problems such as divorce or separation. The aim of this study was to investigate the association and any related gender differences between cancer diagnosis and marital disruption among cancer survivors. Materials and Methods: We used the recent cross-sectional Korea National Health and Nutrition Examination Survey $\left(4^{\text {th }}\right.$ and $5^{\text {th}}$; Years 2008-2012). The study participants were 623 married cancer survivors over the age of 19 . A multivariate logistic regression analysis was conducted to estimate odds ratios. Results: After adjusting for socioeconomic status and health-related behaviors, the odds ratio of marital disruption among female cancer survivors compared with male cancer survivors was 3.94 (95\% CI 1.30-11.94; $\mathrm{p}=0.02)$. The odds ratio of marital disruption for the below-average economic level compared with the above-average economic level was 5.64 (95\% CI: 1.03-31.02; $\mathbf{p}=\mathbf{0 . 0 5}$ ). When compared with the non-smoking cancer survivors, the smoking cancer survivors had an OR of marital disruption equal to $2.94(95 \% \mathrm{CI}$ : $1.08-8.00 ; p=0.03)$. Conclusions: The findings of this study suggest that the odds of marital disruption among female cancer survivors are higher than those among their male couterparts. Medical practitioners should be sensitive to early signs of marital discord in couples affected by a cancer diagnosis. Early identification and psychosocial intervention might reduce the frequency of divorce and separation and thus improve quality of life and quality of care for cancer survivors.
\end{abstract}

Keywords: marital disruption - female - divorces - separation - cancer survivor

Asian Pac J Cancer Prev, 15 (16), 6547-6552

\section{Introduction}

Cancer is the most common cause of death in Korea. Recently, the survival rate among patients with cancer has been improving consistently. It was reported that the fiveyear survival rate from 2007 to 2011 was around $66.3 \%$ and that one out of every 100 people is a cancer survivor (Korea Central Cancer Registry, 2014). The impact of cancer on life trajectory depends not only on diseaserelated factors, treatment factors, and possible late effects but also on life circumstances such as personal resources, socioeconomic status, and social support (Northouse et al., 2005; Ahmad Kiadaliri et al., 2012) (Nazik et al., 2014). A substantial proportion of social support is provided by partners, and married patients with cancer have consistently been found to benefit from such support in terms of better survival rates compared with unmarried patients with cancer (Kato et al., 1992; Kvikstad et al., 1995; Johansen et al., 1996; Ezat et al., 2012).

It might be reasonable to hypothesize, however, that a major life event such as a diagnosis of cancer would have a considerable effect on the quality of marriage and that patients with cancer are therefore at increased risk of marital disruptions such as divorce and separation. At the same time, marital disruption can increase the risks of an unhealthy lifestyle, which may include increased alcohol consumption and tobacco smoking, reduced physical activity, and an unhealthy diet. Such changes can subsequently increase the risk of recurrence and comorbidity and jeopardize survival (Doyle et al., 2006; Ozturk et al., 2014).

Cancer as a 'major life event' imposes huge economic and mental burdens on patients and families. To our knowledge, most studies have failed to find sufficient evidence to verify a relationship between cancer and divorce and other marital problems such as separation. A Danish cohort study suggested that cancer patients face the same challenges with regard to divorce as people who have never been confronted with cancer (Carlsen et al., 2007). Moreover, studies suggest that some couples find that cancer strengthens their relationship (Rieker et al., 1989; Schover and von Eschenbach, 1985). Other studies show, 
however, that some special cancers such as breast cancer and cervix cancer result in marital disruption. Based on some studies, there are some significant differences between males and females in the association between a history of cancer diagnosis and the marital relationship. A Swedish register-based study found that women who were diagnosed with breast cancer had a significant, nearly $25 \%$ increase in their risk of divorce, whereas men who were with diagnosed prostate cancer had a reduction of more than $40 \%$ in their risk of divorce (Socialstyrelsen, 2006).

Most studies of cancer and marital disruption have focused on cervical cancer and breast cancer. Young age and nullipara are known risk factors for divorce (Christoffersen, 2002; Majeed et al., 2014; Mohammadi et al., 2013; Tuncay, 2014; Yan et al., 2014). Furthermore, the treatment of cervical cancer and breast cancer might also affect sexual behavior (Cull et al., 1993) and body image (Juraskova et al., 2003; Hawighorst-Knapstein et al., 2004), perhaps giving rise to marital disharmony and thereby contributing to a higher risk of divorce and other marital problems.

In South Korea, women's relative economic and political status is lower than that in other developed countries. According to the United Nations Gender Empowerment Measure, which monitors women's autonomy along economic, educational, and political dimensions, Korea ranked 53rd out of 75 countries and was far behind most other developed countries (UNDP, 2006). In Korea, even in the last decade, husbands earn the majority of family incomes. For that and other reasons, women are especially vulnerable to marital problems. Hence, women who are diagnosed with cancer may be more likely than men who are diagnosed with cancer to face problems in their marriage.

We asked: besides the special cases of cervical and breast cancers, whether other types of cancer result in significantly more marital disruptions among females than among males? We selected the six types of cancer that are the most common in Korea: gastric cancer, lung cancer, liver cancer, colorectal cancer, breast cancer, and cervical cancer. We aimed to test whether women are more likely than men to be abandoned by their spouses after a cancer diagnosis using the data from the fourth and fifth Korean National Health and Nutrition Examination Surveys (KNHANES; 2008-2012).

\section{Materials and Methods}

\section{Subjects}

This study was based on data obtained from the fourth and fifth K-NHANES, which were conducted from 2008 to 2012 by the Korea Center for Disease Control and Prevention (KCDC). The sampling protocol for the KNHANES was designed to involve a complex, stratified, multistage, probability-cluster survey of a representative sample of the non-institutionalized civilian population of South Korea. The survey was performed by the Korean Ministry of Health. The target population of the survey was all non-institutionalized civilian Korean individuals aged 1 year or older. The survey employed stratified, multistage probability sampling units based on geographical area, gender, and age, which were determined based on the household registries of the 2005 National Census Registrythe most recent five-year national census in Korea. The total population of the survey from 2008 to 2012 included 45,811 individuals. Individuals who were younger than 19 years of age or who were unmarried $(n=15084)$, as well as those for whom data were missing $(n=2985)$, were excluded, leaving 26742 individuals. Among those individuals, there were 623 married adult cancer survivors, our target population, whom we analyzed in our study. A detailed description of the sampling can be found in the KNHANES report (Korea Center for Disease Control and Prevention \& Ministry of Health and Welfare 2009).

\section{Dependent variables}

We defined a marital disruption as either a separation or a legal divorce. To assess marital disruption, the study participants were asked the question: "Have you ever been married?" Based on the answer, the participants were classified as either Married or Unmarried. If a participant was Married, then he or she was asked: "How's your current marital status?" Based on the answer, the participants were further classified as either Living with Spouse, Separated from Spouse, Widowed, or Divorced. Participants who were classified as Married based on the first question and as Separated from Spouse or Divorced based on the second question were considered to have had a marital disruption; those who were classified as Married based on the first question and as Living with Spouse or Widowed based on the second question were considered not to have had a marital disruption.

\section{Independent variables}

Demographic and socioeconomic factors: The participants were divided into three age groups: 19-39, $40-59$, and $\geq 60$ years of age. The region was classified as urban (Seoul, Busan, Daegu, Incheon, Kwangju, Daejeon, and Woolsan) or rural (Kyungki, Kangwon, Chungkuk, Chungnam, Jonbuk, Jonnam, Kyungbuk, Kyungnam, and Jeju). The level of education was classified as: elementary school or less, middle and high school, college, or higher. Economic level was measured by the household income; the household income was the family income adjusted for the number of family members and categorized as: above average, average, or below average. The participants' occupations were classified as white-collar (administrator, professional, or office worker), blue collar (manufacturing, mining, construction, mechanical work, maintenance, technical installation, and various other types of physical work), and non-employed (housewife or student).

Health-related behavior factors: Health-related behavior categories were considered according to the classifications set out in the KNHANES. In terms of smoking status, the subjects were classified as either smoking or non-smoking. The alcohol consumption variable was grouped into two categories: drinking and non-drinking.

Health status and psychological factors: The stress level of the participants was classified as either "a little bit" or "extremely high". Self-reported depression was evaluated by asking each participant: "Have you ever felt 
Gender Differences in Marital Disruption among Korean Patients with Cancer: Results from KNHANES

depression steadily during 2 weeks?" The participants responded either "No" or "Yes".

\section{Statistical analysis}

A multivariate logistic regression analysis was conducted to investigate the association between marital status and the independent variables. The multivariate logistic regression analysis was adjusted for sex, age, region, education level, economic level, employment, current smoking status, current alcohol consumption, stress level, and depressive state.

The odds ratio (OR) and $95 \%$ confidence interval (CI) were calculated, and the threshold for statistical significance was set at $\mathrm{p}<0.05$. Statistical analyses were performed using SAS software version 9.2 (SAS Institute Inc., Cary, North Carolina, USA) to account for the multistage, stratified survey design and the survey weighting for the estimation of all statistical results.

\section{Results}

Table 1 shows the general characteristics of the 623 married cancer survivors aged 19 years or more. A total of $226(43.2 \%)$ males and $397(56.8 \%)$ females were diagnosed with cancer at the baseline. Among the 623 married cancer survivors, there were 27 marital disruptions (20 divorces and 7 separations).

Table 2 shows the univariate and multivariate logistic analyses of the factors associated with marital disruption among the study subjects.

In the adjusted multivariate analysis, the OR of marital disruption for females compared with males was 3.94 (95\%CI: 1.30-11.94; $\mathrm{p}=0.12$ ).
Considering the economic level, the OR of marital disruption for the average economic level compared with the above-average economic level was 1.69 (95\%CI 0.47$6.09 ; \mathrm{p}=0.43)$ and that for the below-average economic level compared with the above-average economic level was 5.64 (95\%CI: 1.03-31.02; $\mathrm{p}=0.05)$.

When compared with the non-smoking cancer survivors, the smoking cancer survivors had an OR of marital disruption equal to 2.94 (95\% CI: 1.08-8.00; $\mathrm{p}=0.03)$.

\section{Discussion}

In this study, 20 out of 623 cancer survivors were divorced. The overall frequency of divorce was $32.1 \%$, which is much higher than the overall divorce rate of 2.4 per 1,000 individuals in Korea in 2012 (Statistics Korea, 2014). This rate was also higher than that found in prior studies, which suggested that the overall frequency of divorce among cancer patients is in the 5-17\% range (Glantz et al., 2009). Prior studies have shown that a cancer diagnosis can bring increased marital distress (Hassali et al., 2013; Kirchhoff et al., 2012). Married couples facing a cancer diagnosis encounter additional health-related, emotional, and financial stressors compared with other couples.

We analyzed the relationship between gender and marital disruption, adjusting for age, region, education level, economic status, employment, current smoking status, current alcohol consumption, stress awareness, and self-reported depression. The results of the multivariate logistic regression analysis showed that the OR of marital disruption for female cancer survivors compared with

Table 1. The Characteristics of Study Participants of Cancer Survivors

\begin{tabular}{|c|c|c|c|c|c|c|c|}
\hline \multirow[t]{2}{*}{ Variables } & & \multicolumn{2}{|c|}{ Divorced+Separated } & \multicolumn{2}{|c|}{ Normal marriage } & \multirow{2}{*}{$\begin{array}{c}\text { Total } \\
\mathrm{N}\end{array}$} & \multirow[t]{2}{*}{$*$ p value } \\
\hline & & $\mathrm{N}$ & $(\%)$ & $\mathrm{N}$ & $(\%)$ & & \\
\hline \multirow[t]{2}{*}{ Sex } & Male & 7 & $(3.1)$ & 219 & $(96.9)$ & 226 & 0.19 \\
\hline & Female & 20 & $(5.0)$ & 377 & $(95.0)$ & 397 & \\
\hline \multirow[t]{3}{*}{ Age (years) } & $19-39$ & 2 & $(14.3)$ & 12 & $(85.7)$ & 14 & 0.07 \\
\hline & $40-59$ & 11 & $(5.4)$ & 192 & $(94.6)$ & 203 & \\
\hline & $\geq 60$ & 14 & (3.4) & 392 & $(96.6)$ & 406 & \\
\hline \multirow[t]{2}{*}{ Region } & Rural & 13 & (3.7) & 334 & $(96.3)$ & 347 & 0.40 \\
\hline & Urban & 14 & $(5.1)$ & 262 & $(94.9)$ & 276 & \\
\hline \multirow[t]{3}{*}{ Education level } & $\leq$ Elementary school & 6 & $(3.0)$ & 196 & $(97.0)$ & 202 & 0.30 \\
\hline & Middle or high school & 15 & $(4.3)$ & 333 & (95.7) & 348 & \\
\hline & $\geq$ College & 6 & $(8.2)$ & 67 & $(91.8)$ & 73 & \\
\hline \multirow[t]{3}{*}{ Economic level } & Rich (above average) & 6 & (4.7) & 123 & (95.3) & 129 & 0.61 \\
\hline & Average & 9 & (3.2) & 269 & $(96.8)$ & 278 & \\
\hline & Poor (blow average) & 12 & (5.6) & 204 & (94.4) & 216 & \\
\hline \multirow[t]{3}{*}{ Employment } & White collar jobs & 18 & (4.6) & 374 & $(95.4)$ & 392 & 0.26 \\
\hline & Blue collar jobs & 5 & (2.8) & 175 & (97.2) & 180 & \\
\hline & No job/student/house wife & 4 & (7.8) & 47 & $(92.2)$ & 51 & \\
\hline \multirow[t]{2}{*}{ Smoking } & Non-smoking & 18 & (3.6) & 477 & (96.4) & 495 & 0.34 \\
\hline & Smoking & 9 & (7.0) & 119 & $(93.0)$ & 128 & \\
\hline \multirow[t]{2}{*}{ Drinking } & Non-drinking & 15 & (3.3) & 440 & (96.7) & 455 & 0.07 \\
\hline & Drinking & 12 & (7.1) & 156 & $(92.9)$ & 168 & \\
\hline \multirow[t]{2}{*}{ Stress awareness } & Extremely high & 7 & (4.4) & 153 & (95.6) & 160 & 0.48 \\
\hline & A little bit & 20 & (4.3) & 443 & $(95.7)$ & 463 & \\
\hline \multirow[t]{2}{*}{ Self-reported Depressive } & Yes & 4 & $(3.0)$ & 131 & $(97.0)$ & 135 & 0.14 \\
\hline & No & 23 & (4.7) & 465 & $(95.3)$ & 488 & \\
\hline Total & & 27 & (4.3) & 596 & (95.7) & 623 & \\
\hline
\end{tabular}

* P values from Pearson's Chi-square test 
Hai-Yan Song et al

Table 2. The Univariate and Multivariate Logistic Regression Analysis (Factors Associated with Marital Disruption)

\begin{tabular}{|c|c|c|c|c|c|c|c|}
\hline \multirow[t]{2}{*}{ Variables } & & \multicolumn{2}{|c|}{ Univaraite analysis } & \multirow[t]{2}{*}{$\mathrm{p}$ value } & \multicolumn{2}{|c|}{ Multivariable analysis } & \multirow[t]{2}{*}{$\mathrm{p}$ value } \\
\hline & & OR & $95 \% \mathrm{CI}$ & & OR & $95 \% \mathrm{CI}$ & \\
\hline \multirow[t]{2}{*}{ Sex } & Male & 1.00 & & & 1.00 & & \\
\hline & Female & 1.99 & $(0.71-5.60)$ & 0.19 & 3.94 & $(1.30-11.94)$ & 0.02 \\
\hline \multirow[t]{3}{*}{ Age (years) } & $19-39$ & 6.36 & $(0.94-43.17)$ & 0.06 & 5.41 & $(0.27-109.13)$ & 0.27 \\
\hline & $40-59$ & 1.90 & $(0.77-4.71)$ & 0.17 & 2.20 & $(0.54-8.98)$ & 0.27 \\
\hline & $\geq 60$ & 1.00 & & & 1.00 & & \\
\hline \multirow[t]{2}{*}{ Region } & Rural & 1.00 & & & 1.00 & & \\
\hline & Urban & 1.47 & $(0.60-3.63)$ & 0.40 & 1.26 & $(0.46-3.48)$ & 0.65 \\
\hline \multirow[t]{3}{*}{ Education level } & $\leq$ Elementary school & 1.00 & & & 1.00 & & \\
\hline & Middle or high school & 1.61 & $(0.53-4.88)$ & 0.40 & 1.42 & $(0.46-4.36)$ & 0.54 \\
\hline & $\geq$ College & 2.79 & $(0.78-9.95)$ & 0.11 & 2.38 & $(0.64-8.81)$ & 0.20 \\
\hline \multirow[t]{3}{*}{ Economic level } & Rich (above average) & 1.00 & & & 1.00 & & \\
\hline & Average & 1.60 & $(0.51-5.06)$ & 1.00 & 1.69 & $(0.47-6.09)$ & 0.42 \\
\hline & Poor (blow average) & 1.60 & $(0.51-5.06)$ & 0.42 & 5.64 & $(1.03-31.02)$ & 0.05 \\
\hline \multirow[t]{3}{*}{ Employment } & White collar jobs & 1.00 & & & 1.00 & & \\
\hline & Blue collar jobs & 0.51 & $(0.16-1.66)$ & 0.27 & 0.44 & $(0.09-2.03)$ & 0.29 \\
\hline & No job/student/house wife & 1.77 & $(0.51-6.15)$ & 0.37 & 1.31 & $(0.33-5.23)$ & 0.70 \\
\hline \multirow[t]{2}{*}{ Smoking } & Non-smoking & 1.00 & & & & 1.00 & \\
\hline & Smoking & 1.60 & $(0.60-4.29)$ & 0.35 & 2.94 & $(1.08-8.00)$ & 0.03 \\
\hline \multirow[t]{2}{*}{ Drinking } & Non-drinking & 1.00 & & & 1.00 & & \\
\hline & Drinking & 2.31 & $(0.91-5.87)$ & 0.08 & 2.63 & $(0.81-8.61)$ & 0.11 \\
\hline \multirow[t]{2}{*}{ Stress awareness } & Extremely high & 1.00 & & & 1.00 & & \\
\hline & A little bit & 1.42 & $(0.54-3.75)$ & 0.48 & 1.23 & $(0.49-3.08)$ & 0.66 \\
\hline \multirow[t]{2}{*}{ Self-reported Depressive } & Yes & 1.00 & & & 1.00 & & \\
\hline & No & 2.49 & $(0.71-8.76)$ & 0.15 & 3.21 & $(0.82-12.61)$ & 0.10 \\
\hline
\end{tabular}

male cancer survivors was 3.94 (95\%CI: 1.30-11.94; $\mathrm{p}=0.02$ ). This result implies that a diagnosis of cancer brings a higher risk of marital disruption to women than to men. One explanation for this result may be the low social status of South Korean women.

Women in South Korea have recently experienced great social change, improving their social status over the last 30 years. Despite this evidence of official equality, questions remain about the true nature of the improvement in women's social status and gender-equality; inequality persists in some areas, such as the scarcity of women in professional fields, the prevalent imbalance of housework, the coherent belief in gender differences, and other factors. Korea still remains a patriarchal society.

According to some researches, wives who work very long hours as paid employees are more likely to divorce or separate than wives who are out of the labor force (Shin et al., 2014; Yean-Ju and 2008), and a wife's employment increases the chance of marital disruption (Jolovaara and Marika, 2003; Poortman et al., 2002; Schoen et al., 2002). Some studies argue that a wife's income allows her to walk away from an unhappy marriage; researchers call this the "independence effect", in contrast to the "income effect", which refers to the stabilizing effect of incomes on marriages (Oppenheimer and Valerie, 1997; Sayer and Bianchi, 2000; Yu-soon, 2005). In South Korea, although increasing numbers of women work outside the home, the dominant conception, particularly for the college-educated middle class, is that the husband is the "outside person", whose employment provides the main source of economic support, whereas the wife is the "inside person", whose chief responsibility is the maintenance of the household. The rate of labor-force participation among married women from 15 to 49 years of age is approximately $40 \%$ in urban areas according to the 2000 census, and the average wage for women is $61 \%$ that of men (KOSIS, 2008). Women tend to leave the labor force when they get married. Many women manage the family finances, and informal private short-term credit associations give them access to funds that might not be obtainable from a conventional bank. The most important responsibility of married women is probably the management of their children's education.

In South Korea, because of their low social status and low labor-force participation rate, women are generally at a disadvantage to men within a marriage. After a cancer diagnosis, the situation will be even worse, because women can no longer perform their usual roles within the household and can no longer take care of the families. At such times, husbands may look down upon their spouses and choose to leave or abandon them.

From Table 2, the OR of marital disruption for individuals with below-average incomes compared with those with above-average incomes was 5.64 (95\% CI: $1.03-31.02 ; \mathrm{p}=0.05)$, and that for individuals with average incomes compared with those with above-average incomes was 1.69 (95\%CI: 0.47-6.09; $\mathrm{p}=0.43$ ). In fact, higher levels of marital stability among couples with higher socioeconomic status have already been observed (Bernardi et al., 2011; Esping-Andersen, 2009; salvini et al., 2011). In other words, lower economic status results in a higher risk of marital disruption, which is the same as the finding of our study.

The OR of marital disruption for cancer survivors who smoke compared with those who do not smoke was 2.94 (95\%CI: 1.08-8.00; $\mathrm{p}=0.0347)$. One explanation for this result may be that the impact of smoking and marital disruption is bidirectional; the result may also be explained 
by a higher rate of smoking among cancer survivors who had marital disruptions compared with those who did not. A cohort study conducted in the United States found that women who became divorced or widowed had an increased risk of relapsing or starting to smoke (Lee et al., 2005).

Although age is known to be a strong risk factor for divorce and separation (Christoffersen, 2002; Socialstyrelsen, 2006), we found a negative (albeit nonsignificant because of the small sample size) trend in marital disruption as age increased. Marital relationships, in particular, may be strained for younger cancer patients as they face health-related, emotional, and financial stressors as a result of the cancer. For married couples, as cancer diagnosis can bring increased marital distress, uncertainty about a partner's health, problems with sexual functioning and fertility, as well as added financial stress and instability (Avci and Kumcagiz, 2011; Gurney et al., 2009). However, the impact of cancer on marital outcomes among young adults may be unique because of the complex lifestyle and social changes that occur during young adulthood. Marriage can bring significant social and emotional support to young cancer patients as well as provide important resources during treatment and recovery through a spouse's income and health insurance coverage. Younger marriages may be less resilient to the stresses of cancer treatment and recovery, however, and they may face competing burdens of having young children or lower job security than older couples. Among young cancer survivors, the increased emotional and financial burdens of cancer may impact on marriages in ways not seen among other survivor populations.

Compared with other individuals with cancer, young cancer survivors may have a higher risk of divorce and separation, although our findings cannot support such a conclusion, possibly because the sample of young cancer survivors was very small. Future studies could expand the sample size and explore the effects of age on the likelihood of marital disruptions due to cancer through case-control and cohort studies.

To our knowledge, this study is the first to use the data from the KNHANES to try to determine whether female cancer survivors are at a higher risk than male cancer survivors of being abandoned by their spouses in Korea. The advantage of this study is that we used the KNHANES, which was designed as a complex, stratified, multistage, probability-cluster survey and thus excludes the possibility of selection biases.

There are several limitations to our study, however. First, because the subjects of our study were cancer survivors, information on cancer status is important, such as the cancer stage, the time of the first diagnosis, and whether or not complications exist. We could not confirm those factors, because the KNHANES did not include such information. Second, all information in the KNHANES was collected by the participants' responses to questions, so information biases may exist. For example, the rates of reported smoking and alcohol drinking might have been underestimated, whereas stress awareness and self-reported depression might have been overestimated. Third, our study did not include information on the participants' children, such as how many children were in the household and the ages of the children and also some other psychosocial factors such as depression, which are known to be risk factors for marital disruption. One of the most important limitations of our study is the crosssectional design, which made it difficult for us to identify causal relationships between marital disruption and gender and other associated factors.

In conclusion, the risk of partner abandonment following a cancer diagnosis was higher among women than among men, so we recommend that medical practitioners be especially sensitive to early signs of marital discord in couples affected by the occurrence of a serious medical illness such as cancer, especially when the affected spouse is female. Early identification and psychosocial intervention might reduce the frequency of divorce and separation and thus improve the quality of life and quality of care for cancer survivors.

\section{References}

Ahmad Kiadaliri A, Bastani P, Ibrahimipour H (2012). Healthrelated quality of life of breast cancer patients in Iran: pooled analysis using generalized estimating equations. Asian Pac $J$ Cancer Prev, 13, 941-4.

Avci IA , Kumcagiz H (2011). Marital adjustment and loneliness status of women with mastectomy and husbands reactions. Asian Pac J Cancer Prev, 12, 453-9.

Bernardi F, Juan-Ignacio, Martinez-Pastor (2011). Divorce risk factors and their variation over time in Spain. Demographic Research, 24.

Carlsen K, Dalton SO, Frederiksen K, et al (2007). Are cancer survivors at an increased risk for divorce? A Danish cohort study. Eur J Cancer, 43, 2093-9.

Christoffersen M (2002). Dissolved families.

Cull A, Cowie V, Farquharson D, et al (1993). Early stage cervical cancer: psychosocial and sexual outcomes of treatment. Br J Cancer, 86, 1216-20.

Doyle C, Kushi L, Byers T, et al (2006). Nutrition and physical activity during and agter cancer treatment: an American Cancer Society guide for informed choices. CA Cancer $J$ Clin, 56, 323-53.

Esping-Andersen G (2009). The Incomplete revolution: adapting welfare states to women's new roles. Cambridge, UK: Polity Press.

Ezat WP, Noraziani K, Sabrizan O (2012). Improving quality of life among cancer patients in Malaysia. Asian Pac J Cancer Prev, 13, 1069-75.

Glantz MJ, Chamberlain MC, Liu Q, et al (2009). Gender disparity in the rate of partner abandonment in patients with serious medical illness. Cancer, 115, 5237-42.

Gurney J, Krull K, Kadan-Lottick N, et al (2009). Social outcomes in the childhood cancer survivor study cohort. $J$ Clin Oncol, 27, 2390-5.

Hassali MA, Knight A, Shafie AA, et al (2013). Cross sectional assessment of health related quality of life (HRQoL) among patients with cancer in Malaysia. Asian Pac J Cancer Prev, 14, 3017-21.

Hawighorst-Knapstein S, Fusshoeller C, Franz C, et al (2004). The impact of treatment for genital cancer on quality of life and body image- results of a prospective longitudinal 10-year study. Gynecol Oncol, 94, 398-403.

Johansen C, Schou G, Soll-Johanning H, et al (1996). Influence of marital status on survival from colon and rectal cancer in Denmark. Br J Cancer, 74, 985-8. 
Hai-Yan Song et al

Jolovaara, Marika (2003). The joint effects of marriage partners' socioeconomic positions on the risk of divorce. Demography, 40, 67-81.

Juraskova I, Butow P, Robertson R, et al (2003). Post-treatment sexual adjustment following cervical and endometrial cancer: a qualitative insight. Psychooncology, 12, 267-79.

Kato I, Tominaga S, Ikari A (1992). The role of socioeconomic factors in the survival of patients with gastrointestinal cancers. Jpn J Chin Oncol, 22, 270-7.

Kirchhoff AC, Yi J, Wright J, et al (2012). Marriage and divorce among young adult cancer survivors. J Cancer Survive, $\mathbf{6}$, 441-50.

Kvikstad A, Vatten L, Tretli S (1995). Widowhood and divorce in relation to overall survival among middle-aged Norwegian women with cancer. Br J Cancer, 71, 1343-7.

Lee S, Cho E, Grodsein F, et al (2005). Effects of marital transitions on change in dietary and other health behaviours in US women. Int J Epidemiol, 34, 69-78.

Majeed W, Aslam B, Javed I, et al (2014). Breast cancer: major risk factors and recent developments in treatment. Asian Pac J Cancer Prev, 15, 3353-8.

Mohammadi S, Sulaiman S, Koon PB, et al (2013). Association of nutritional status with quality of life in breast cancer survivors. Asian Pac J Cancer Prev, 14, 7749-55.

Nazik E, Ozdemir F, Soydan S (2014). Social support and quality of life in Turkish patients with gynecologic cancer. Asian Pac J Cancer Prev, 15, 3081-6.

Northouse L, Kershaw T, Mood D, Schafenacher A (2005). Effects of a family intervention on the quality of life of women with recurrent breast cancer and their family caregivers. Psychooncology, 22, 270-7.

Oppenheimer, Valerie K (1997). Women's employment and the gain to marriage: the specialization and trading model. Annual Review of Sociology, 23, 431-53.

Ozturk C, Bektas M, Mert O (2014). Effects of cigarette smoking across three generations and of perceptions of the smokingcancer relationship on the cigarette smoking status of turkish university students. Asian Pac J Cancer Prev, 15, 4527-33.

Poortman, Anne-Right, Kalmijn M (2002). Women's labor market position and divorce in netherlands: evaluating economic interpretations of the work effect. Eur J Popul, 18, 110-29.

Rieker P, Fitzgerald E, Kalish L, et al (1989). Psychosocial factors, curative therapies, and behavioral outcomes. A comparison of testis cancer survivors and a control group of healthy men. Cancer, 64, 2399-407.

salvini, Silvana, Vignoli D (2011). Things change: women's and men's marital disruption dynamics in Italy during a time of social transformations, 1970-2003. Demographic Research, 24, 145-74.

Sayer LC, Bianchi SM (2000). Women's Economic Independence and the Probability of Divorce. J Fam Issues, 21, 906-43.

Schoen, Robert, Astone NM, et al (2002). Women's Employment, marital Happiness, and Divorce. Social Forces, 81, 643-62.

Schover L, von Eschenbach A (1985). Sexual and marital relationships after treatment for nonseminomatous testicular cancer. Urology, 25, 251-5.

Shin S, Kim YH, Hwang JS, et al (2014). Economic evaluation of prostate cancer screening test as a national cancer screening program in South Korea. Asian Pac J Cancer Prev, 15, 3383-9.

Socialstyrelsen (2006). In 'Social rapport 2001', in Swedish pp 140-1.

Tuncay T (2014). Coping and quality of life in Turkish women living with ovarian cancer. Asian Pac J Cancer Prev, 15, 4005-12.

Yan J, Pan L, Zhang X, et al (2014). Lack of efficacy of tai chi in improving quality of life in breast cancer survivors: a systematic review and meta-analysis. Asian Pac J Cancer Prev, 15, 3715-20.

Yean-Ju L, (2008). Socioeconomic determinants of divorce/ separation in south Korea: a focus on wife's current and desired employment characteristics. Development and Society, 37, 117-39.

Yu-soon LM-SaK (2005). Factors affecting inclination to divorce with respect to the causes of divorce: a comparison between male and female models. Women's Studies, 69, 35-91 